\title{
Social Networks among the Older Chinese Population in the USA: Findings from the PINE Study
}

\author{
XinQi Dong E-Shien Chang \\ Chinese Health, Aging, and Policy Program, Rush Institute for Healthy Aging, Chicago, IL, USA
}

\section{Keywords}

Social networks $\cdot$ Well-being $\cdot$ Aging $\cdot$ Immigration

\begin{abstract}
Background: Social network research has become central to studies of health and aging. Its results may yield public health insights that are actionable and improve the quality of life of older adults. However, little is known about the social networks of older immigrant adults, whose social relationships often develop in the context of migration, compounded by cultural and linguistic barriers. Objectives: This report aims to describe the structure, composition, and emotional components of social networks in the Chinese aging population of the USA, and to explore ways in which their social networks may be critical to their health decision-making. Methods: Our data come from the PINE study, a population-based epidemiological study of community-dwelling older Chinese American adults, aged 60 years and above, in the greater Chicago area. We conducted individual interviews in participants' homes from 2011 until 2013. Based on sociodemographic and socioeconomic characteristics, this study computed descriptive statistics and trend tests for the social network measures adapted from the National Social Life, Health, and Aging Project study. Results: The findings
\end{abstract}

show that older Chinese adults have a relatively small social network in comparison with their counterparts from other ethnic and racial backgrounds. Only $29.6 \%$ of the participants could name 5 close network members, and $2.2 \%$ could name 0 members. Their network composition was more heavily kin oriented (95.0\%). Relationships with network members differed according to the older adults' sociodemographic and socioeconomic characteristics. Subgroup variations included the likelihood of discussing health-related issues with network members. Conclusion: This study highlights the dynamic nature of social networks in later-life Chinese immigrants. For healthcare practitioners, developing cost-effective strategies that can mobilize social network support remains a critical undertaking in health intervention. Longitudinal studies are needed to examine the causal impact of social networks on various domains of health.

(c) 2017 S. Karger AG, Basel

\section{Introduction}

The social network paradigm is one of the most prominent analytical frameworks used in social-behavioral research. First introduced by sociologists in 1961 [1], social network studies have contributed greatly to our under-

\section{KARGER}

(c) 2017 S. Karger AG, Basel

E-Mail karger@karger.com

www.karger.com/ger
XinQi Dong, MD, MPH, Professor of Geriatric and Internal Medicine

Chinese Health, Aging, and Policy Program

Rush Institute for Healthy Aging, 1645 West Jackson, Suite 675

Chicago, IL 60612 (USA)

E-Mail xinqi_dong@rush.edu 
standing of the complexity of social relations across the life span. Subsequent lines of public health scientific inquiry have emerged and shifted the focus onto describing how social networks may play an even more critical role in later-life health and well-being [2], during which older adults experience additional frailty and vulnerabilities. Findings from cross-sectional and prospective studies of aging populations consistently document that a dysfunctional social network is associated with adverse health outcomes, including medical comorbidities, increased risks of dementia, psychological distress, and mortality $[3,4]$. More recent research also suggests that social networks play an important role in determining one's health behaviors and health decision-making process [5].

The process of network formation operates differently across social strata as well as across cultural contexts. Cross-cultural variation in the linkage between social networks and health is particularly evident. Empirical studies in the USA and Europe have linked patterns and types of social networks to health outcomes. For instance, based on an area probability sample of American older adults in Michigan, Fiori et al. [6] reported that the impact of an absence of friends in the context of family support is more detrimental to health than the absence of family support in the context of friends. In another US study that examines community-dwelling older adults' social network characteristics, researchers found that even after controlling for social structural variables, racial differences between African-Americans and Caucasians persist in the characteristics of social networks [7]. When applying social network analysis to familism-oriented cultures, researchers found different health outcomes in familybased networks than in other types such as friendshipbased networks [8]. Older adults with a higher proportion of family members in their social networks reported better overall health compared to those with fewer close family members. Based on the results from the Chinese Longitudinal Health Longevity Survey, Li and Zhang [9] further reported that the friend-focused type was more beneficial to Chinese older adults' physical health outcomes, while the family-oriented type yielded higher levels of psychological well-being over time. However, both the composition and the perceived quality of the relationships in the social networks would likely be related to older adults' health and health-related decision-making processes [10].

In addition, immigrant older adults may be more susceptible to the disruption of social network change brought about by their relocation and transitory statuses. The existent majority of the literature on immigration, social network, and health suggests that compared to nativeborn older adults, immigrant older adults may be more dependent on smaller, close-knit social networks for financial, emotional, and social support in later life [11]. On the one hand, older immigrants' reliance on their social networks may instill a sense of community and belongingness in their new settlement [12]. On the other hand, older immigrants' dependence on the few members of their small networks may increase the risks of overburdening these relationships [13]. In addition, the timing of immigration may also be an important point of consideration for social networks among older adults. Those who immigrated earlier in life may have more resources and tools of socialization that enabled them to develop and maintain adequate social ties. Conversely, those who immigrated in later life may experience higher levels of cultural and linguistic barriers; as a result, they may have smaller networks than their counterparts who immigrated earlier in the course of their life [14].

Although the importance of racial, ethnic, cultural, and migrational contexts has been brought to the foreground in aging research involving social network analysis, our knowledge of social networks among older Chinese immigrants is limited. The Chinese community in the USA has been perceived as the "model minority," and its health disparities are often masked under this mythical and ambiguous label. In reality, older adults of Chinese descent - one of the fastest-growing segments of the geriatric population - are faced with disproportionate health burdens, ranging from physical to psychological distress [15]. Although recent studies have begun to examine the dynamic nature of the social relationships of older Chinese immigrants [16], the social networks of this minority group remain underexplored.

\section{Conceptual Framework}

Social networks are defined as the existence, quantity, and quality of relationships [17]. As a critical feature of social well-being, social networks are recognized as the web of relationships that surround an individual and the characteristics of those ties [17]. However, the health benefits of connectedness stem from larger exchanges of social integration. According to Durkheim's social integration theory, social ties with family, friends, and other groups may result in changes to health and well-being due to the controlled and regulated nature of these social ties [18]. Kahn and Antonucci's [19] formation of the "convoy model" has shed additional light on social networks amongst older adults. Namely, stability and changes in one's network arrangements are coexisting features from 
a life course perspective, shaped by individuals' characteristics as well as by how they respond to different life challenges. Following the Durkheimian orientation, Berkman et al. [18] later devised a conceptual framework embedding social networks with cascading pathways into health outcomes and behaviors via social structural conditions at the macro level, and psychosocial mechanisms at the micro level. The pathways describe a cascading causal process. The macrosocial framing forces such as socioeconomic statuses first help shape social networks, which in turn activate psychosocial mechanisms. These mechanisms then subsequently influence health via psychological and biological processes. Hence, it is pivotal to view social networks with respect to the larger social and cultural contexts, as larger social contexts help to shape the structure of networks.

Social network characteristics are composed of structural components, such as network size and homogeneity, as well as the content and quality of the network ties, including the frequency of visual and nonvisual contacts. In addition, restricting social network analysis to isolated aspects of network types or contacts may not be as informative as accounting for other theoretical aspects of social networking, that is, the interactional and emotional components of social networks. Understanding social networks as having a particular array of attributes can be particularly insightful in describing their impact on aging. One of the most versatile and widely applied social network measures was substantiated by the National Social Life, Health, and Aging Project (NSHAP) study, a nationally representative, population-based study of older adults aged $57-85$ years. The NSHAP study utilizes egocentric measures that allow researchers to examine network size, composition, member characteristics, and emotional closeness, as well as to directly quantify the impact of the network on health and healthcare decisionmaking. Empirical evidence, based on the NSHAP study's findings, suggests that older adults in the USA generally have large and dense social networks [20]. However, the social network structure tends to be disrupted over time. Sociodemographic and socioeconomic determinants play a consequential role in shaping older adults' social networks; specifically, members of racial minority groups are more likely to experience barriers to forming and sustaining healthy and supportive social networks in later life.

To fill the knowledge gap, this paper aims to (1) describe social networks, including their size, composition, and associations with health in the older Chinese population, (2) explore how immigrant older adults' social net- work members may be critical to their health and health decision-making, and (3) understand ways in which the social network's structure, quality, and extent may vary depending on the sociodemographic and immigrational characteristics of Chinese older adults.

\section{Design and Methods}

\section{Population and Settings}

The Population Study of Chinese Elderly in Chicago (PINE) is a population-based epidemiological study of community-dwelling older Chinese adults between the ages of 60 and 105 years in the Greater Chicago area [21]. We conducted at-home in-person interviews from 2011 to 2013 . The PINE study aimed to collect community-level data about older Chinese adults by examining a wide array of health and aging issues in the older Chinese population. A synergistic community-academic collaboration initiated the project, including partnerships with the Rush Institute for Healthy Aging, the Northwestern University, and over 20 Greater Chicago area community-based social service agencies and organizations.

To ensure the study's relevance to the well-being of the Chinese community and to increase community participation, a community-based participatory research approach helped guide the project. A community advisory board played a pivotal role in providing insights for our research activities. The board worked extensively with the investigative team to develop and test study instruments to ensure their cultural sensitivity and appropriateness. The PINE study is a representative study of older Chinese adults in the Greater Chicago area [22].

\section{Study Design and Procedure}

Community-dwelling older adults aged 60 years and over who self-identified as Chinese were eligible to participate in the study. The study staff approached prospective participants in social service agencies, community centers, health advocacy agencies, faith-based organizations, senior apartments, and social clubs throughout the Greater Chicago area. Study flyers and program brochures were disseminated in social gatherings in the Chinese community. Those who expressed interest in study participation were subsequently approached by trained research staff in their homes to further explain the study goals, procedure, and consent forms in detail. Prospective participants were then given time to ask questions and encouraged to discuss their voluntary study participation with family members. After obtaining 2 signed copies of the consent forms, the research staff also provided a copy of the consent form to the study participants. Of all eligible older adults approached, 3,159 agreed to participate in the study, yielding a response rate of $91.9 \%$. Trained multicultural and multilingual interviewers conducted face-to-face home interviews with the participants in their preferred language (English or Chinese) and dialect (e.g., Cantonese, Taishanese, Mandarin, or Teochew). The study was approved by the Institutional Review Board of the Rush University Medical Center.

\section{Measurements}

Sociodemographics. Basic demographic information including age (in years), years of education completed, annual personal income (USD 0-4,999 per year, USD 5,000-9,999 per year, USD $10,000-14,999$ per year, USD 15,000-19,999 per year, or more than 
USD 20,000 per year), marital status (married, separated, divorced, or widowed), number of children, number of grandchildren, years in the community, and years in the USA was assessed for all participants. Living arrangements were categorized into 4 groups: (1) living alone, (2) living with 1 person, (3) living with $2-3$ persons, or (4) living with 4 or more persons.

Overall Health Status, Quality of Life, and Health Changes over the Last Year. Overall health status was measured by the question, "In general, how would you rate your health?" on a 4-point scale ( 1 = poor, 2 = fair, 3 = good, and 4 = very good). Quality of life was assessed by asking, "In general, how would you rate your quality of life?" also on a 4-point scale ranging from 1 (poor) to 4 (very good). Health changes over the last year were measured by the question, "Compared to one year ago, how would you rate your health now?" with answer options as 1 (worsened), 2 (no change), and 3 (improved).

Social Networks. Adapted from the NSHAP study [20], our social network measures aimed to understand the relevant set of network members and the types of relationship that connect them. We collected up to 2 rosters per participant. We first asked the participants to list up to 5 people with whom they had discussed important matters in the past year, and these 5 members would be listed in roster $\mathrm{A}$. When respondents had a spouse, romantic partner, or children who were not included in roster A, those individuals were subsequently recorded in roster B.

Having identified the network size, we then collected additional information with respect to network composition, including (1) the relationship to each member (18 types of relationship, including partner, children, children-in-law, grandchildren, friends, etc.), (2) the gender of the members, and (3) whether the participant lives with the member. The quality of such relationships was captured by emotional closeness; we asked the participants to rate how close they are to the network members, with ordinal responses ranging from 1 (not very close) to 4 (extremely close). The volume of contact with network members was examined by the approximate number of times per year participants interacted with network members. We then summed these scores across all members in roster A for a total score of the overall volume of contact. Furthermore, NSHAP modules capture the functional component of network ties with respect to healthcare decision-making. We asked the participants about the likelihood of discussing medical decisions with each of the members listed; ordinal responses ranged from 1 (not likely) to 4 (very likely). If a participant had any spouse, romantic partner, or children who were not listed in roster A, the aforementioned procedure was repeated to document the participant's response for all members listed in roster B.

\section{Data Analysis}

Univariate descriptive statistics were used to summarize demographic, socioeconomic, family structural, and health-related characteristics of the PINE participants. Descriptive statistics for the social network measures were computed according to several sociodemographic statistics. Trend tests were conducted to assess whether the distribution of each network attribute was uniform across the group. Subgroups of age, gender, education, income, and health were converted into separate ordinal scales. Then, each network attribute was linearly regressed separately on each scale. We then report the overall significance. All statistical analyses were undertaken using the Statistical Analysis System (SAS) version 9.2.

Social Networks in Chinese Older Adults
Table 1. Number of network members in the PINE network rosters

\begin{tabular}{|c|c|c|c|c|}
\hline \multicolumn{2}{|l|}{ Roster A } & \multicolumn{3}{|l|}{ Roster B } \\
\hline $\begin{array}{l}\text { number of } \\
\text { members } \\
\text { in roster }\end{array}$ & $n(\%)$ & $\begin{array}{l}\text { number of } \\
\text { members } \\
\text { in roster }\end{array}$ & $\begin{array}{l}\text { spouse, } \\
n(\%)\end{array}$ & $\begin{array}{l}\text { children, } \\
n(\%)\end{array}$ \\
\hline 0 & $69(2.2)$ & 0 & $2,072(91.0)^{\mathrm{a}}$ & $2,113(67.6)$ \\
\hline 1 & $452(14.4)$ & $1+$ & $205(9.0)^{\mathrm{a}}$ & $1,011(32.4)$ \\
\hline 2 & $494(15.8)$ & \multirow{4}{*}{ N/A } & & \\
\hline 3 & $659(21.0)$ & & & \\
\hline 4 & $535(17.1)$ & & & \\
\hline 5 & $927(29.6)$ & & & \\
\hline
\end{tabular}

a $n=2,277 ; 868$ were widowed.

\section{Results}

\section{Number of Network Members on the Rosters}

Of the 3,157 participants, 58.9\% were female. The participants' age ranged from 60 to 105 years, with a mean of 72.8 and a standard deviation (SD) of 8.3 years. The mean number of years of completed education was 8.7 (SD $\pm 5.1)$. The majority of the participants $(85.1 \%)$ received less than USD 10,000 in annual income. Overall, $60.8 \%$ of the participants had a fair or poor health status, $49.3 \% \mathrm{had}$ a fair or poor quality of life, and $42.5 \%$ had experienced a worsened health status in the previous 1 year.

The number of network members listed in rosters A and $B$ is shown in Table 1 . The participants were asked to name up to 5 members in roster A. As a result, the mean number of network members listed in roster A was 3.3 (SD \pm 1.5 ). Only $29.6 \%$ of the participants listed all 5 members. Moreover, $2.2 \%$ of the participants did not identify any members. About $9.0 \%$ of the participants did not include their spouse, and $32.4 \%$ did not include all of their children in roster A. Thus, their spouse and children's information was listed in roster B.

\section{Frequency Comparison of Network Members in Roster A}

Across all 5 network members in roster A, the participants tended to name either their spouse or their children over relatives, friends, or others (Table 2). The majority of the participants (53.2\%) listed their spouse as the first member, followed by their children (38.9\%). The likelihood of naming children ranged from 83.6 to $47.8 \%$ for network members $2-5$. Regarding the age of the network members, the median age of all 5 members ranged from 45.1 to 60.4 years; however, the age range was between 2 
Table 2. Frequency comparison of network members in roster $A$

\begin{tabular}{|c|c|c|c|c|c|}
\hline & Member 1 & Member 2 & Member 3 & Member 4 & Member 5 \\
\hline \multicolumn{6}{|c|}{ Participants who named network } \\
\hline members, $n(\%)$ & $3,067(97.7)$ & $2,616(83.5)$ & $2,123(67.9)$ & $1,462(46.8)$ & $927(29.6)$ \\
\hline \multicolumn{6}{|c|}{ Relationship with the member, $\%$} \\
\hline Spouse & 53.2 & 6 & 4.7 & 5.3 & 7.7 \\
\hline Children & 38.9 & 83.6 & 81.3 & 68.5 & 47.8 \\
\hline Sibling & 1.9 & 2.6 & 3.1 & 6.9 & 9.4 \\
\hline Friend & 2.7 & 2.3 & 2.9 & 6.2 & 11 \\
\hline Other family members & 2.5 & 5.2 & 7.5 & 11.3 & 19.4 \\
\hline Others & 0.9 & 1.6 & 1 & 2.1 & 4.5 \\
\hline \multicolumn{6}{|l|}{ Member's age, years } \\
\hline Mean (SD) & $60.4(14.3)$ & $46.3(13.3)$ & $45.1(13.0)$ & $48.1(15.2)$ & $51.4(17.4)$ \\
\hline Range & $8-105$ & $2-95$ & $2-96$ & $2-97$ & $3-97$ \\
\hline \multicolumn{6}{|c|}{ Member's age in comparison with participant, $\%$} \\
\hline Older & 21.4 & 4.8 & 4.1 & 6.7 & 10.5 \\
\hline Same & 6.5 & 1.5 & 1.2 & 2.8 & 6.6 \\
\hline Younger & 72.1 & 93.7 & 94.7 & 90.5 & 82.9 \\
\hline \multicolumn{6}{|l|}{ Gender, \% } \\
\hline Male & 44.7 & 49.6 & 47.5 & 43.3 & 40.3 \\
\hline Female & 55.3 & 50.4 & 52.5 & 56.7 & 59.7 \\
\hline \multicolumn{6}{|l|}{ Living arrangement, \% } \\
\hline Co-residence & 58.5 & 23.8 & 14.5 & 11.6 & 12.9 \\
\hline No co-residence & 41.5 & 76.2 & 85.5 & 88.5 & 87.2 \\
\hline \multicolumn{6}{|l|}{ Volume of contact, \% } \\
\hline Every day & 70.0 & 38.1 & 27.5 & 0.2 & 23.1 \\
\hline Several times a week & 16.2 & 28.4 & 28.6 & 0.3 & 25.3 \\
\hline Once a week & 9.0 & 20.7 & 23.7 & 4.2 & 26.1 \\
\hline Once every 2 weeks & 2.0 & 5.9 & 9.1 & 9.0 & 10.3 \\
\hline Once a month & 1.7 & 4.4 & 7.0 & 10.9 & 10.8 \\
\hline A couple times a year & 0.9 & 2.0 & 3.4 & 24.9 & 3.9 \\
\hline Once a year & 0.1 & 0.2 & 0.5 & 26.9 & 0.4 \\
\hline Less than once a year & 0.2 & 0.2 & 0.2 & 23.6 & 0.1 \\
\hline \multicolumn{6}{|l|}{ Closeness of relationship, $\%$} \\
\hline Extremely close & 58.3 & 51.2 & 48.1 & 45.7 & 37.4 \\
\hline Very close & 33.0 & 38.3 & 40.9 & 42.1 & 46.5 \\
\hline Somewhat close & 7.8 & 9.4 & 9.7 & 11.1 & 14.6 \\
\hline Not very close & 1.0 & 1.1 & 1.3 & 1.1 & 1.5 \\
\hline \multicolumn{6}{|c|}{ Likelihood of sharing important medical decisions, $\%$} \\
\hline Very likely & 92.2 & 87.9 & 85.0 & 81.2 & 73.2 \\
\hline Somewhat likely & 5.3 & 7.8 & 9.5 & 12.3 & 15.7 \\
\hline Not likely & 2.5 & 4.3 & 5.6 & 6.5 & 11.2 \\
\hline
\end{tabular}

and 105 years. The participants commonly listed members of female gender (50.4-59.7\%). With respect to living arrangements and the volume of contact, the first network member tended to be living with the participant (58.5\%), and with this person there was contact on a daily basis. Regarding closeness of the relationship, the majority of the participants identified a very close to an extremely close relationship with network members; this ranged from 91.3 to $83.9 \%$ for all network members. The same trend was observed regarding the likelihood of sharing important medical decisions; this ranged from 92.2 to $73.2 \%$ for all network members.

\section{Sociodemographic Distribution of Key Social Network Measures}

An additional analysis of the descriptive statistics was performed to examine the sociodemographic distribution of the social network members. Trend tests were per- 
formed to understand whether the distribution of each network characteristic was consistent across the study participants (Table 3).

With respect to the structural aspects of the social network, the participants reported a mean size of 3.25 network members $(\mathrm{SD} \pm 1.49$ ). Younger age groups were more likely to identify a larger network size than older age groups $(p<0.005)$. Female participants reported slightly larger network sizes, although the trend was not statistically significant $(p=0.50)$. Regarding socioeconomic status, older adults with higher income indicated a larger network size $(p<0.05)$, while educational levels were demonstrated to have no statistically significant impact on network size. Participants with a very good quality of life tended to report larger network sizes than did those with a poor quality of life $(p<0.001)$.

Older Chinese adults' networks are largely kin centered in terms of network composition. Across all age groups, nearly $95-96 \%$ of the participants' networks were composed of kin. Older male adults with lower education and income reported a higher proportion of kin $(p<$ 0.005). For illiterate participants, $97 \%$ of their networks were kin. With respect to gender, older age groups (above 75 years of age) tended to report having more female confidants than did younger age groups $(p<0.05)$. Men reported having more female confidants than did women ( 65 vs. $47 \%, p<0.001$ ). With respect to health status, however, the proportion of kin or female confidants did not impact the distribution of self-reported health, quality of life, or health changes in the past year. Our findings further suggest that those who immigrated at an older age tended to have a larger network size, a larger proportion of kin members in their networks, a larger proportion of female network members, a smaller proportion of network members who lived in the same household, higher levels of closeness, and a higher volume of contact days $(p<0.001)$ than those older adults who immigrated at a younger age.

\section{Emotional Closeness to Network Members and Contact Volume}

Regarding the emotional components of social networks, overall, older Chinese adults felt close to network members (mean $=3.4, \mathrm{SD} \pm 0.60$; the score ranged from 1 to 4 , with the higher scores indicating higher levels of emotional closeness) (Table 3). However, participants over 85 years of age $(p<0.001)$ who were male $(p<0.05)$ and who had received less education $(p<0.05)$ reported less closeness to their network members. Compared to the other network characteristics reported above, there were more significant differences in emotional closeness across the levels of self-reported health status. Participants reporting higher levels of emotional closeness with network members were likely to indicate good or very good self-reported health, as well as a good or very good quality of life $(p<0.001)$.

On average, older adults reported 1.85 contacts per day with a close network member (675.9/365). Participants of older age reported fewer contacts per year $(p<0.001)$. However, there were no statistically significant differences in the contact volume with respect to participants' gender, education, or self-reported health status.

\section{Sociodemographic Characteristics of the Spouse and Children in Roster $B$}

We now consider the sociodemographic characteristics of members listed in roster B, namely, participants' spouses and adult children who were not amongst the initial 5 persons with whom they would discuss important matters (Table 4 ). In total, $9.0 \%$ of the participants did not name their spouse. In this subset of the cohort, more women than men listed their spouse ( 54.4 vs. $45.6 \%$ ), and $35.7 \%$ of the participants did not live with their spouse. Despite the fact that over half of the participants (57.5\%) reported daily contact with their spouse, $38.5 \%$ indicated the unlikelihood of discussing medical decisions with them. With respect to the characteristics of children not listed in roster A, the majority of the children did not coreside with the participants $(90.2-96.2 \%)$, and contact most likely took place once a week (22.5-33.3\%).

\section{Network Members in Health Discussions}

We further examined whether the likelihood of involving network members in health-related discussions differed by relationship type (Table 5 ). In the aggregate, older adults were more likely to have health discussions with their spouse $(89.3 \%)$ compared to with other types of members. Older adults were also more likely to discuss their health with female network members, those who were middle-aged and in the youngest-old group (aged 40-70 years), and those who resided in the same household. Also, older adults were more likely to discuss health matters with those they felt close to and with those who were in higher frequency of contact. A total of $64.4 \%$ of the older adults indicated that they were unlikely to discuss health-related matters with members that they deemed as "not very close." The results from Table 6 further suggest that the relationship type and likelihood of discussing health are not the same across the participants' age at immigration. 
Table 3. Participants' sociodemographic distributions by key social network measures (mean number \pm SD)

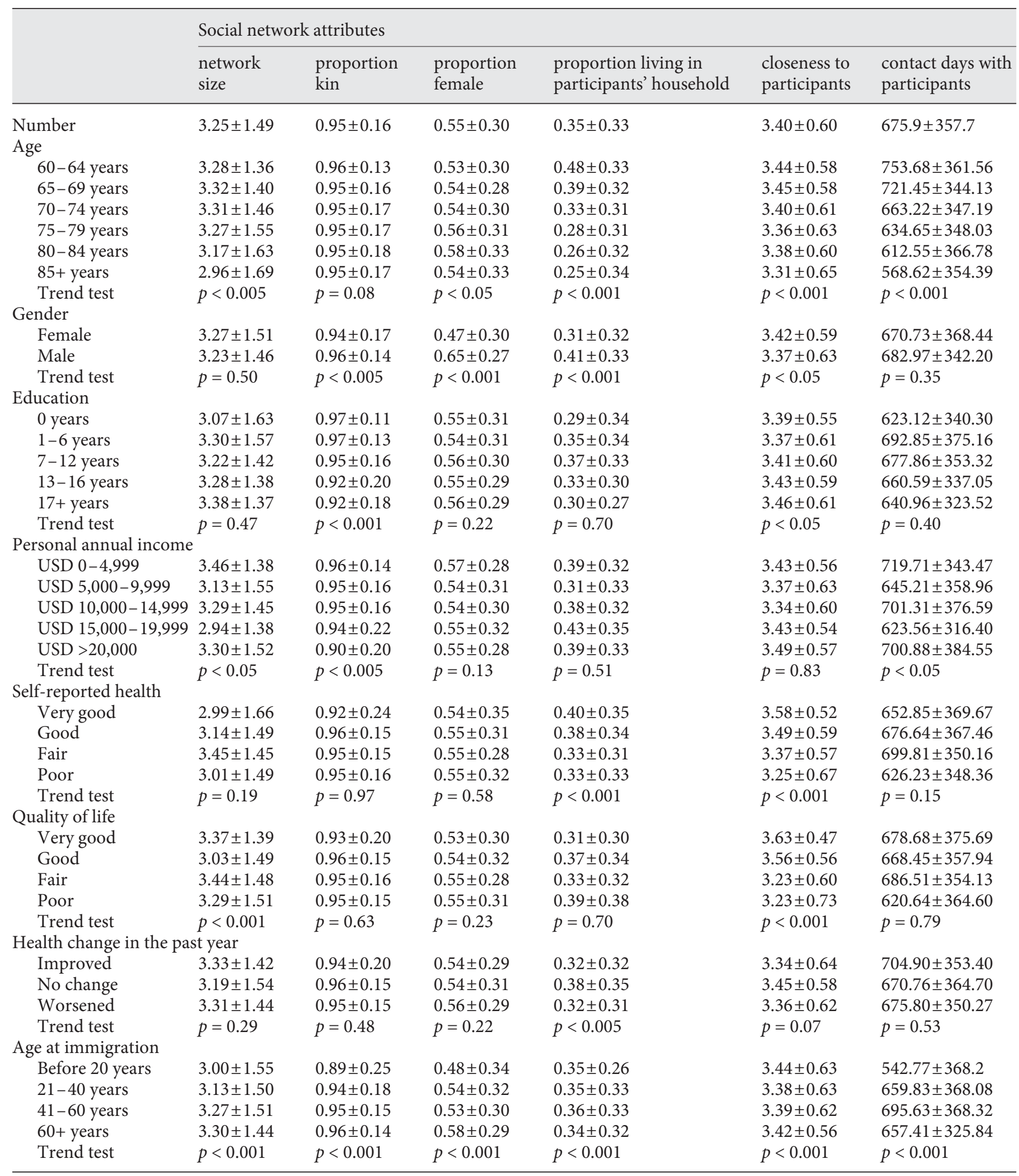


Table 4. Sociodemographic characteristics of roster B

\begin{tabular}{|c|c|c|c|c|c|}
\hline \multicolumn{4}{|l|}{ Spouse characteristics if not listed in roster $A$} & $n$ & $\%$ \\
\hline \multicolumn{6}{|l|}{ Gender } \\
\hline \multicolumn{4}{|l|}{ Male } & 109 & 53.1 \\
\hline \multicolumn{4}{|l|}{ Female } & 96 & 46.8 \\
\hline \multicolumn{6}{|l|}{ Living arrangement } \\
\hline \multicolumn{4}{|l|}{ Co-residence } & 128 & 63.1 \\
\hline \multicolumn{4}{|l|}{ No co-residence } & 75 & 37.0 \\
\hline \multicolumn{6}{|l|}{ Age in comparison with respondent } \\
\hline \multicolumn{4}{|l|}{ Older } & 94 & 46.3 \\
\hline \multicolumn{4}{|l|}{ About the same age } & 13 & 6.4 \\
\hline \multicolumn{4}{|l|}{ Younger } & 96 & 47.3 \\
\hline \multicolumn{6}{|l|}{ Volume of contact } \\
\hline \multicolumn{4}{|l|}{ Every day } & 110 & 57.6 \\
\hline \multicolumn{4}{|l|}{ Several times a week } & 24 & 12.6 \\
\hline \multicolumn{4}{|l|}{ Once a week } & 21 & 11.0 \\
\hline \multicolumn{4}{|l|}{ Once every 2 weeks } & 5 & 2.6 \\
\hline \multicolumn{4}{|l|}{ Once a month } & 8 & 4.2 \\
\hline A couple of times a year & & & & 8 & 4.2 \\
\hline Once a year & & & & 1 & 0.5 \\
\hline Less than once a year & & & & 14 & 7.3 \\
\hline Closeness of relationship & & & & & \\
\hline Extremely close & & & & 56 & 28.3 \\
\hline Very close & & & & 56 & 28.3 \\
\hline Somewhat close & & & & 44 & 22.2 \\
\hline Not very close & & & & 42 & 21.2 \\
\hline Likelihood of sharing important medical decisi & & & & & \\
\hline Very likely & & & & 79 & 39.7 \\
\hline Somewhat likely & & & & 44 & 22.1 \\
\hline Not likely & & & & 76 & 38.2 \\
\hline & Child 1 & Child 2 & Child 3 & Child 4 & Child 5 \\
\hline Characteristics of children if not listed by respor & at in roster & & & & \\
\hline $\begin{array}{l}\text { Number of respondents who named children } \\
\text { Age, years }\end{array}$ & 374 & 187 & 79 & 26 & 12 \\
\hline Mean \pm SD & $44.2 \pm 9.6$ & $43.3 \pm 9.2$ & $44.0 \pm 9.2$ & $45.9 \pm 7.7$ & $44.7 \pm 6.0$ \\
\hline Range & $5-80$ & $12-61$ & $16-70$ & $35-65$ & $37-54$ \\
\hline Gender, \% & & & & & \\
\hline Male & 51.1 & 48.2 & 47.5 & 53.9 & 33.3 \\
\hline Female & 48.9 & 51.8 & 52.5 & 46.2 & 66.7 \\
\hline Living arrangement, \% & & & & & \\
\hline Co-residence & 9.8 & 5.8 & 5.0 & 3.9 & 8.3 \\
\hline No co-residence & 90.2 & 94.2 & 95.0 & 96.2 & 91.7 \\
\hline Volume of contact, $\%$ & & & & & \\
\hline Every day & 14.9 & 7.9 & 10.0 & 11.5 & 16.7 \\
\hline Several times a week & 18.6 & 20.6 & 20.0 & 19.2 & 25.0 \\
\hline Once a week & 27.4 & 25.9 & 22.5 & 26.9 & 33.3 \\
\hline Once every 2 weeks & 9.6 & 11.6 & 15.0 & 11.5 & 0.0 \\
\hline Once a month & 10.4 & 11.1 & 10.0 & 15.4 & 8.3 \\
\hline A couple of times a year & 9.6 & 13.2 & 15.0 & 3.9 & 8.3 \\
\hline Once a year & 2.9 & 1.1 & 2.5 & 0.0 & 8.3 \\
\hline Less than once a year & 6.7 & 8.5 & 5.0 & 11.5 & 0.0 \\
\hline Closeness of relationship, $\%$ & & & & & \\
\hline Extremely close & 30.9 & 29.1 & 17.5 & 26.9 & 8.3 \\
\hline Very close & 38.1 & 40.2 & 53.8 & 42.3 & 58.3 \\
\hline Somewhat close & 19.5 & 18.5 & 17.5 & 15.4 & 25.0 \\
\hline Not very close & 11.5 & 12.2 & 11.3 & 15.4 & 8.3 \\
\hline Likelihood of sharing important medical decisi & $\%$ & & & & \\
\hline Very likely & 57.2 & 51.9 & 50.0 & 42.3 & 33.3 \\
\hline Somewhat likely & 20.6 & 28.6 & 30.0 & 30.8 & 50.0 \\
\hline Not likely & 22.2 & 19.6 & 20.0 & 26.9 & 16.7 \\
\hline
\end{tabular}


Table 5. Likelihood of including social network members in health-related discussions by network members' characteristics $(n=11,077$ members $)$

\begin{tabular}{|c|c|c|c|}
\hline & \multicolumn{3}{|c|}{$\begin{array}{l}\text { Likelihood of discussing health with } \\
\text { member, } n(\%)\end{array}$} \\
\hline & $\begin{array}{l}\text { very } \\
\text { likely }\end{array}$ & $\begin{array}{l}\text { somewhat } \\
\text { likely }\end{array}$ & $\begin{array}{l}\text { not } \\
\text { likely }\end{array}$ \\
\hline \multicolumn{4}{|l|}{ Relationship type } \\
\hline Spouse & $2,001(89.3)$ & $118(5.3)$ & $123(5.5)$ \\
\hline Child & $6,180(85.5)$ & $708(9.8)$ & $339(4.7)$ \\
\hline Sibling & $288(76.0)$ & $52(13.7)$ & $39(10.3)$ \\
\hline Other relative & $469(66.3)$ & $106(15.0)$ & $132(18.7)$ \\
\hline Friend & $256(64.5)$ & $79(19.9)$ & $62(15.6)$ \\
\hline Others & $49(39.2)$ & $42(33.6)$ & $34(27.2)$ \\
\hline \multicolumn{4}{|l|}{ Age } \\
\hline $1-10$ years & $12(20.3)$ & $5(8.5)$ & $42(71.2)$ \\
\hline $11-20$ years & $43(39.5)$ & $18(16.5)$ & $48(44.0)$ \\
\hline $21-30$ years & $390(39.5)$ & $56(11.6)$ & $36(7.5)$ \\
\hline $31-40$ years & $2,170(87.0)$ & $205(8.2)$ & $120(4.8)$ \\
\hline $41-50$ years & $2,499(84.3)$ & $320(10.8)$ & $146(4.9)$ \\
\hline $51-60$ years & $1,438(83.8)$ & $184(10.7)$ & $95(5.5)$ \\
\hline $61-70$ years & $1,325(85.0)$ & $151(9.7)$ & $83(5.3)$ \\
\hline $71-80$ years & $853(83.6)$ & $78(7.7)$ & $89(8.7)$ \\
\hline $81-90$ years & $271(75.7)$ & $41(11.5)$ & $46(12.9)$ \\
\hline $90+$ years & $15(53.6)$ & $3(10.7)$ & $10(35.7)$ \\
\hline \multicolumn{4}{|l|}{ Sex } \\
\hline Male & $4,170(81.3)$ & $561(10.9)$ & $399(7.8)$ \\
\hline Female & $5,073(85.3)$ & $544(9.2)$ & $330(5.6)$ \\
\hline \multicolumn{4}{|l|}{ Co-residence status } \\
\hline Co-resident & $2,898(90.7)$ & $175(5.5)$ & $122(3.8)$ \\
\hline Not co-resident & $6,341(80.5)$ & $930(11.8)$ & $607(7.7)$ \\
\hline \multicolumn{4}{|l|}{ Frequency of contact } \\
\hline$\geq$ Several times a week & $6,526(91.9)$ & $360(5.1)$ & $216(3.0)$ \\
\hline$<$ Several times a week & $2,704(68.5)$ & $743(18.8)$ & $503(12.7)$ \\
\hline \multicolumn{4}{|l|}{ Emotional closeness } \\
\hline Extremely close & $5,069(93.7)$ & $180(3.3)$ & $160(3.0)$ \\
\hline Very close & $3,531(82.8)$ & $513(12.0)$ & $219(5.1)$ \\
\hline Somewhat close & $600(51.6)$ & $369(31.8)$ & $193(16.6)$ \\
\hline Not very close & $42(17.6)$ & $43(18.0)$ & $154(64.4)$ \\
\hline
\end{tabular}

\section{Discussion}

Social network analyses have become central in studies of health and aging. To our knowledge, the current descriptive study is amongst the first endeavors to comprehensively depict the structure, composition, and emotional components of social networks in the older Chinese population. Relationships with network members largely depend on the older adults' sociodemographic and socioeconomic characteristics. The subgroup variations also extended to the likelihood of discussing health- related issues with network members. Overall, only some components of social networks had close links to participants' self-reported health status.

At first glance, older Chinese adults identified smaller and more kinship-based social networks when compared to the US general population. Utilizing identical social network measures as the NSHAP study allowed us to compare them directly with the network characteristics of the US older adults in the NSHAP study. Whereas $36.8 \%$ of the NSHAP study cohort identified at least 5 members in their networks, only $29.6 \%$ of the older Chinese adults had the same results [20]. Also, a total of $2.2 \%$ of the Chinese older adults did not list any members in roster $\mathrm{A}$, in comparison to $1.8 \%$ of the NSHAP study cohort. The parallel comparison suggests that Chinese older adults are more likely to have smaller networks and a proportionately greater potential for social isolation.

This report's findings on network member characteristics lend support to previous studies suggesting that older adults from more familism-oriented cultural backgrounds identify larger proportions of kin-centered networks. In the US Latino population, nearly $80 \%$ of the older adults' networks were kin based [20]. The present study found an even larger proportion of Chinese older adults who identified kin-centered networks (95\%). Kin relationships often are the source most likely to provide unconditional support during health crises [23]. Besides the needs of reaching out to kin members during health crises, what is more consequential for Chinese older adults may be the cultural indoctrination of family-oriented filial piety values. Family cohesiveness remains a deeply valued social norm for Chinese older adults, both in China and overseas, expressed in the form of high filial expectations of adult children [23] in addition to serving as a robust protective factor against psychological distress [24]. Previous social network analyses in Hong Kong have indicated that kin-based networks can be further divided into immediate kin and distant kin, both of which are associated with older adults' subjective wellbeing [25]. Our finding is consistent with previous USbased research in racial minority groups that suggested racial and ethnic differences in network size and kinship proportion [26]. For instance, on average, AfricanAmerican older adults tended to have smaller social networks than their Caucasian counterparts, although African-Americans reported a higher proportion of kin in their networks [27]. These patterns of smaller, kinshipbased social networks may be more evident in minority groups and are often explained to occur due to the strategies employed among the ethnic/racial minority groups 
Table 6. Likelihood of including social network members in health discussions by participants' age at immigration and network members' characteristics ( $n=11,030$ members)

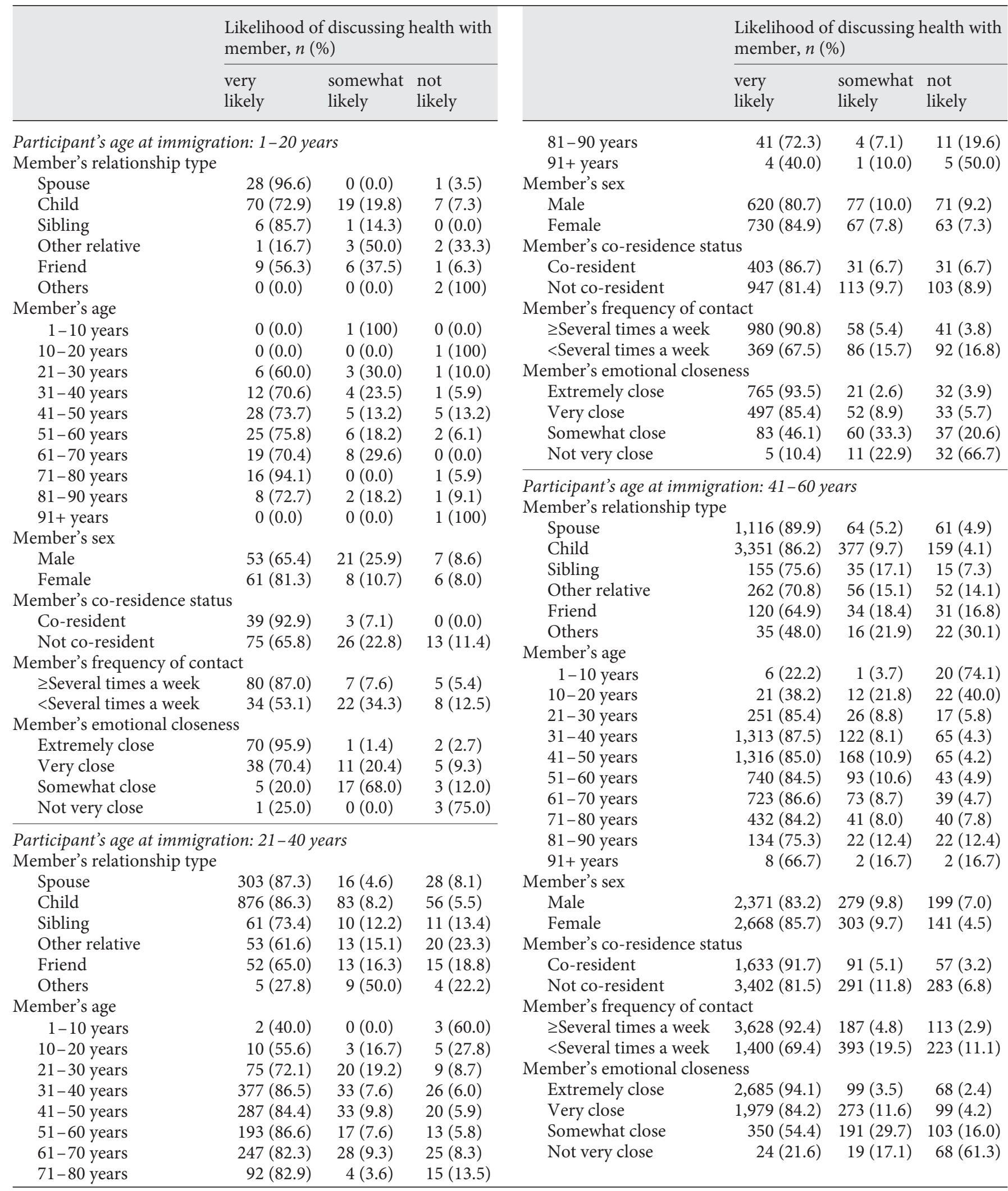


Table 6 (continued)

\begin{tabular}{|c|c|c|c|c|c|c|c|}
\hline & \multicolumn{3}{|c|}{$\begin{array}{l}\text { Likelihood of discussing health with } \\
\text { member, } n(\%)\end{array}$} & & \multicolumn{3}{|c|}{$\begin{array}{l}\text { Likelihood of discussing health with } \\
\text { member, } n(\%)\end{array}$} \\
\hline & $\begin{array}{l}\text { very } \\
\text { likely }\end{array}$ & $\begin{array}{l}\text { somewhat } \\
\text { likely }\end{array}$ & $\begin{array}{l}\text { not } \\
\text { likely }\end{array}$ & & $\begin{array}{l}\text { very } \\
\text { likely }\end{array}$ & $\begin{array}{l}\text { somewhat } \\
\text { likely }\end{array}$ & $\begin{array}{l}\text { not } \\
\text { likely }\end{array}$ \\
\hline \multicolumn{4}{|c|}{ Participant's age at immigration: $61+$ years } & $81-90$ years & $87(77.7)$ & $13(11.6)$ & $12(10.7)$ \\
\hline \multicolumn{4}{|l|}{ Member's relationship type } & $91+$ years & $3(75.0)$ & $0(0.0)$ & $1(25.0)$ \\
\hline Spouse & $548(88.8)$ & $38(6.2)$ & $31(5.0)$ & Member's sex & & & \\
\hline Child & $1,863(84.5)$ & $224(10.2)$ & $117(5.3)$ & Male & $1,112(78.5)$ & $183(12.9)$ & $121(8.6)$ \\
\hline Sibling & $63(76.8)$ & $6(7.3)$ & $13(15.9)$ & Female & $1,596(85.4)$ & $155(8.3)$ & $118(6.3)$ \\
\hline Other relative & $151(62.4)$ & $33(13.6)$ & $58(24.0)$ & \multicolumn{4}{|c|}{ Member's co-residence status } \\
\hline Friend & $74(66.1)$ & $24(21.4)$ & $14(12.5)$ & Co-resident & $814(90.9)$ & $49(5.5)$ & $33(3.7)$ \\
\hline Others & $9(32.1)$ & $13(46.4)$ & $6(21.4)$ & Not co-resident & $1,894(79.3)$ & $289(12.1)$ & $206(8.6)$ \\
\hline Member's age & & & & \multicolumn{4}{|c|}{ Member's frequency of contact } \\
\hline $1-10$ years & $4(15.4)$ & $3(11.5)$ & $19(73.1)$ & $\geq$ Several times a week & $1,813(91.9)$ & $104(5.3)$ & $56(2.8)$ \\
\hline $10-20$ years & $12(34.3)$ & $3(8.6)$ & $20(57.1)$ & $<$ Several times a week & $894(68.4)$ & $234(17.0)$ & $179(13.7)$ \\
\hline $21-30$ years & $57(78.1)$ & $7(9.6)$ & $9(12.3)$ & \multicolumn{4}{|c|}{ Member's emotional closeness } \\
\hline $31-40$ years & $462(86.2)$ & $46(8.6)$ & $28(5.2)$ & Extremely close & $1,525(93.0)$ & $57(3.5)$ & $56(3.5)$ \\
\hline $41-50$ years & $865(84.1)$ & $109(10.6)$ & $55(5.3)$ & Very close & $1,011(80.0)$ & $171(13.5)$ & $82(6.5)$ \\
\hline $51-60$ years & $475(82.2)$ & $66(11.4)$ & $37(6.4)$ & Somewhat close & $160(52.1)$ & $98(31.9)$ & $49(16.0)$ \\
\hline $61-70$ years & $334(85.0)$ & $40(10.2)$ & $19(4.8)$ & Not very close & $0.12(16.0)$ & $12(16.0)$ & $51(68.0)$ \\
\hline $71-80$ years & $308(82.5)$ & $33(8.9)$ & $32(8.6)$ & & & & \\
\hline
\end{tabular}

because of economic deprivation and racial discrimination [28]. Minority older adults are most likely to place trust on their family members, explaining partially the consistent findings of smaller, majority kin-based social networks among minority older adults. However, small networks may not be as helpful when older adults are reaching out to additional resources beyond the immediate network. Future research should systematically investigate how patterns of network characteristics that have been shown to differ by racial/ethnic group affect well-being and health.

This study also showed that participants with lower education and income reported a larger proportion of kin contacts $(p<0.005)$. Congruent with existing data on social networks, socially disadvantaged older adults may rely disproportionally on kin network members for social support as well as for indirect access to the resources for wellness [29]. On the other hand, older adults with higher income may be more able to remain integrated within a social network, because of their ability to afford diversified activities and transportation [30]. In light of the high proportion of kin-based networks, researchers may find the distinction between different family roles and corresponding health functions increasingly important in understanding the social networks of older Chi- nese immigrants. This literature would also be strengthened by greater attention to the role of socioeconomic status in the restriction of social networks and the effect of such changes on later-life health. Our preliminary findings further suggest that age at immigration may play an important role in immigrants' social networks and health decision-making. The previous literature reports that immigrants with higher levels of ethnic attachment and lower levels of English proficiency are more likely to have greater emotional and tangible network support. For example, Kim [31] found that Korean-American older adults who had a strong ethnic attachment tend to maintain and develop intimate network relationships with Koreans, including family and nonfamily members, and receive a greater amount of emotional and tangible support from them. Similarly, Diwan [32] reported that Asian-Indian immigrants' social networks differed by their length of stay in the USA; those who had shorter residence in the USA had greater reliance on family networks and less frequent interactions with friends. However, she did not find any differences in their rates of depressive symptoms despite different social network structures. This mechanism of interplay between immigration, social network characteristics, and health warrants our further attention. More research is needed to 
understand the impact of immigration on social network formations and its relationships to health outcomes. Future studies should further explore the network patterns and characteristics by the level of acculturation among immigrant older adults, as this may help fine-tune health promotion activities by addressing within-group differences.

Despite the trend toward largely kin-based social networks, there remain older Chinese adults who did not name their spouse or all of their children as key confidants. There are a few explanations for this absence of immediate family confidants. First, despite the fact that the cultural doctrine of filial piety remains strong in Chinese communities, the reality may be different in the post-immigration context. For older Chinese adults in the USA, family members have become an even more vital form of support in the face of cultural and linguistic challenges, as compared to their counterparts in their place of origin. However, older adults' increased dependency may lead to higher levels of vulnerability if the family support expectations are unmet. While family tension may be a by-product of such frustrations, further acculturative conflicts and caregiver burdens may predispose older adults to elder abuse, domestic violence, and associated adverse health outcomes [33]. Consequently, older adults may shift their expectations away from their immediate family to extended family or friends as a coping mechanism [34]; alternatively, they may experience greater levels of social isolation. Further research is needed to understand the specific processes responsible for the potential shifts in network composition. In particular, given the large volume of health literature indicating that children's support contributes more to the life satisfaction of older Chinese adults than the support of friends $[24,35]$, further inquiry is needed to examine the health consequences of such changes in this subgroup of participants.

Second, from focus groups and field interview experience, older adults have expressed sentiments of voluntarily reducing their expectations of adult children, fearing that they may be overburdening their immigrant adult children who may be equally challenged by the cultural and linguistic barriers in the USA [23]. Traditionally, Chinese culture prioritizes the collective welfare of the family over individual attainment. In the context of migration, every family member is expected to work hard toward the collective goal of achieving the American dream. As a result, older adults may attempt to manage their resources and health issues by drawing on other resources such as local community service centers. Never- theless, qualitative studies concur that older Chinese adults hoped that their children would provide more instrumental support, care, and resources [23]. Adult children's perspectives regarding their parents' social relationships may provide further insights into these dynamics.

Third, perhaps split-household family residential patterns are common across all immigrant families. Many older adults in this study still have immediate family members in their home country awaiting visa clearance for a family reunion. This structural barrier may reduce the likelihood of confiding in immediate family members who are geographically distant. Instead, older adults may opt for building local social networks in ethnic enclaves or neighborhoods in close proximity. Variations of the transnational social network warrant further consideration in depicting the potentially diverse social relations of immigrant communities.

In terms of older age, and consistent with some evidence that social disconnectedness may become more prevalent with increasing age [35], our findings suggest that the oldest group was most likely to have smaller networks and fewer co-resident members. The oldest group also reported the least intensity in emotional closeness, as well as the lowest frequency of contacts relative to the younger age groups. This is contrary to some studies that suggest that older adults, faced with shrinking social networks, may develop closer relationships with fewer confidants as a proactive mechanism against social isolation [36]. There may be a few plausible explanations for why immigrant older adults concurrently experienced fewer connections and a lower quality of these relationships. First, in general, immigrant older adults often encounter some degree of social isolation due to their low acculturation levels. For Chinese older adults, moving to a new country equates to disconnection from their existing contacts in a collectivist community-orientated society. Compared to those older adults who age in the same place, the possibility of reaching out and establishing new confidants may be quite slim in the face of cultural and linguistic barriers. Second, it is possible that the volume of contacts declines with age due to deteriorating health, as indicated by previous prospective studies [9]. Furthermore, it is also likely that worsening functional health limits older adults' ability to sustain an existing frequency of contact, which in turn may decrease the level of emotional closeness. Longitudinal studies are needed to examine the reciprocal relationship between older age and the quality and quantity of social contacts in the immigrant population. The ways in which structural 
components of the network may interact with the emotional aspects of closeness in old age warrant further exploration.

With respect to gender, our findings concur with a prior understanding that network size may not differ significantly between men and women [37]. However, compared to the women, the older men in this study reported a somewhat less diversified network composition; the men had a larger proportion of confidants who were female, were kin, and resided in the same household. Also, the older men exhibited lower levels of emotional closeness with existing confidants when compared with the women. In general, women are more likely to participate in social activities and community engagement, and, therefore, they have more heterogeneous sources and contacts of network members outside their home [16]. However, this previous work did not specifically include older age groups when gender differences regarding mortality occurred, resulting in more women in widowhood and single households. Consequently, older women may be prompted to expand beyond the existing kinshipbased network, as compared to older men, who continue to rely on their spouses. Conversely, men may have a larger group of family confidants living in the same household, but they do not necessarily feel close to those confidants. One postulation may be that older women experience greater emotional intensity and greater comfort from emotional experiences than men [38]. While prior gerontological research has elucidated women's relatively high vulnerability to psychological distress with respect to loneliness and isolation, older men may be equally vulnerable to the health consequences of dysfunctional social relationships [39].

When considering the effects of the quality and quantity of contacts on health, the present study indicated that emotional closeness has closer ties to health status as compared to the volume of contact. Participants with stronger emotional bonds reported better health and quality of life. Due to the cross-sectional nature of the data, it is also plausible that those participants with better health are more likely to maintain emotional closeness with their confidants. Nonetheless, this report lends support to existing studies indicating that quality of support is one mechanism by which network connectedness is related to self-reported health measures [23]. Furthermore, the quality of network support may play a role in mediating network structure and health. Future health interventions that focus on measures to deepen emotional ties with network confidants may be most beneficial to the well-being of older Chinese adults.

\section{Limitations}

The study findings need to be considered within the limitations of the present inquiry. First of all, the crosssectional nature of the analysis prevents us from precluding causal effects of social networks and self-reported health. The literature suggests that older adults' social networks may be subject to changes over time with respect to their structure and characteristics [40]. In-depth studies are needed to assess longitudinal social network data in immigrant communities and their implications for the health of older adults in the domains of physical, cognitive, and psychological well-being. Also, a mixedmethods approach will be insightful in understanding the rationale behind confidant preferences. Second, due to the time limit on the survey, information regarding network density or the network bridging potential, which could further expand our understanding of network dynamics, was not collected. Future studies should consider collecting these additional variables to visualize network dynamics and member interaction within each network roster. Last, this study was representative of older Chinese adults in the Greater Chicago area; thus, its findings should not be generalized to other aging populations. Nonetheless, this study is a first step in exploring sociodemographic differences and self-reported health status in the social networks of older immigrant adults.

\section{Implications}

Social networks have wide implications for the health of aging immigrant adults. For geriatric practitioners, integrating older adults' social networks into clinical assessment may be insightful in enriching the levels of care coordination. Since the structure of a social network often shapes the resources available to the individual, particular care should be delivered to those with limited social network confidants, who are at higher risk of social isolation. In the light of the fact that the social network plays an important role in assisting older adults with health concerns, the informal care provided to this subset of older adults continues to warrant public attention.

Furthermore, social network analysis can yield actionable public health insights that may improve the quality of life of older adults. Differing from other measurements of social support, social network analysis can help public health practitioners to identify those relationships and persons that extend beyond traditional kinship or residential groups to explain individuals' healthcare decision-making processes. Therefore, developing cost-effective strategies that can mobilize social network support remains a critical undertaking in health- 
care intervention. While current randomized control trials have sought to modify network structures so as to impact health behaviors in different age groups, limited research has been conducted in older populations or in minority groups. This limitation highlights the necessity of approaching social networks not only in terms of social-behavioral traits but also in relation to public health epidemiology.

\section{Conclusion}

The present study highlights the dynamic nature of social networks in later-life Chinese immigrants. There are substantial differences in older adults' experiences of social networks in terms of composition and emotional connectedness, based on age, gender, and socioeconomic status, in the aged Chinese population. Longitudinal studies are needed to examine the potential for network changes over time, as well as the causal impact of social networks on various domains of health and aging.

\section{References}

1 Thompson WE, Streib GF: Meaningful activity in a family context; in Kleemeier R (ed): Aging and Leisure: A Research Perspective on the Meaningful Use of Time. Oxford, Oxford University Press, 1961.

2 House JS, Umberson D, Landis KR: Structures and processes of social support. Annu Rev Soc 1988;14:293-318.

3 Litwin H, Shiovitz-Ezra S: Network type and mortality risk in later life. Gerontologist 2006; 46:735-743.

4 Fratiglioni L, Wang HX, Ericsson K, Maytan M, Winblad B: Influence of social network on occurrence of dementia: a community-based longitudinal study. Lancet 2000;355:13151319.

5 Wonodi CB, Privor-Dumm L, Aina M, Pate AM, Reis R, Gadhoke P, Levine OS: Using social network analysis to examine the decisionmaking process on new vaccine introduction in Nigeria. Health Policy Plan 2012;27(suppl 2):ii27-ii38

6 Fiori KL, Antonucci TC, Cortina KS: Social network typologies and mental health among older adults. J Gerontol B Psychol Sci Soc Sci 2006;61:P25-P32.

7 Peek MK, O’Neill GS: Networks in later life: an examination of race differences in social support networks. Int J Aging Hum Dev 2001; 52:207-229.

8 Webster NJ, Antonucci TC, Ajrouch KJ, Abdulrahim S: Social networks and health among older adults in Lebanon: the mediating role of support and trust. J Gerontol B Psychol Sci Soc Sci 2015;70:155-166.

9 Li T, Zhang Y: Social network types and the health of older adults: exploring reciprocal associations. Soc Sci Med 2015;130:59-68.

10 Krause N: Negative interaction and satisfaction with social support among older adults. J Gerontol B Psychol Sci Soc Sci 1995;50:P59P74.
11 Almeida J, Molnar BE, Kawachi I, Subramanian SV: Ethnicity and nativity status as determinants of perceived social support: testing the concept of familism. Soc Sci Med 2009;68: 1852-1858.

12 Rote S, Markides K: Aging, social relationships, and health among older immigrants. Generations, Spring 2014. http://www.asaging.org/blog/aging-social-relationships-andhealth-among-older-immigrants.

13 Viruell-Fuentes EA, Schulz AJ: Toward a dynamic conceptualization of social ties and context: implications for understanding immigrant and Latino health. Am J Public Health 2009;99:2167-2175.

14 Weeks JR, Cuellar JB: Isolation of older persons: the influence of immigration and length of residence. Res Aging 1983;5:369-388.

15 Dong X: Addressing health and well-being of US Chinese older adults through communitybased participatory research: introduction to the PINE Study. J Gerontol A Biol Sci Med Sci 2014;69(suppl 2):S1-S6.

16 Chen R, Simon MA, Chang ES, Zhen Y, Dong $\mathrm{X}$ : The perception of social support among US Chinese older adults: findings from the PINE Study. J Aging Health 2014;26:1137-1154.

17 Laumann E, Marsden P, Prensky D: The boundary specification problem in network analysis; in Burt RS, Minor MJ (eds): Applied Network Analysis: A Methodological Introduction. London, Sage, 1983, pp 18-34.

18 Berkman L, Glass T, Brissette I, Seeman TE: From social integration to health: Durkheim in the millennium. Soc Sci Med 2000;51:843857.

19 Kahn RL, Antonucci TC: Convoys over the life course: attachment, roles, and social support. Life Span Dev Behav 1980;3:253-286.

20 Cornwell B, Schumm LP, Laumann EO, Graber J: Social networks in the NSHAP study: rationale, measurement, and preliminary findings. J Gerontol B Psychol Sci Soc Sci 2009;64(suppl 1):i47-i55.
21 Dong X, Wong E, Simon MA: Study design and implementation of the PINE study. J Aging Health 2014;26:1085-1099.

22 Simon MA, Chang ES, Rajan KB, Welch MJ, Dong X: Demographic characteristics of US Chinese older adults in the Greater Chicago area: assessing the representativeness of the PINE study. J Aging Health 2014;26:11001115.

23 Dong X, Chang ES, Wong E, Simon MA: A qualitative study of filial piety among community dwelling, Chinese, older adults: changing meaning and impact on health and well-being. J Intergener Relatsh 2012;10:131146.

24 Simon MA, Chen R, Chang ES, Dong X: The association between filial piety and suicidal ideation: findings from a community-dwelling Chinese aging population. J Gerontol A Biol Sci Med Sci 2014;69(suppl 2):S90-S97.

25 Cheng ST, Lee CK, Chan AC, Leung EM, Lee JJ: Social network types and subjective wellbeing in Chinese older adults. J Gerontol B Psychol Sci Soc Sci 2009;64:713-722.

26 Park NS, Jang Y, Lee BS, Ko JE, Haley WE, Chiriboga DA: An empirical typology of social networks and its association with physical and mental health: a study with older Korean immigrants. J Gerontol B Psychol Sci Soc Sci 2015;70:67-76

27 Ajrouch KJ, Antonucci TC, Janevic MR: Social networks among blacks and whites: the interaction between race and age. J Gerontol B Psychol Sci Soc Sci 2001;56:S112-S118.

28 Roschelle AR: No More Kin: Exploring Race, Class, and Gender in Family Networks. Thousand Oaks, Sage, 1997.

29 Cornwell B: Social disadvantage and network turnover. J Gerontol B Psychol Sci Soc Sci 2015;70:132-142. 
30 Unger JB, McAvay G, Bruce ML, Berkman L, Seeman T: Variation in the impact of social network characteristics on physical functioning in elderly persons: MacArthur Studies of Successful Aging. J Gerontol B Psychol Sci Soc Sci 1999;54:S245-S251.

31 Kim O: Mediation effect of social support between ethnic attachment and loneliness in older Korean immigrants. Res Nurs Health 1999;22:169-175.

32 Diwan S: Limited English proficiency, social network characteristics, and depressive symptoms among older immigrants. J Gerontol B Psychol Sci Soc Sci 2008;63:S184-S191.
33 Dong X, Chang ES, Wong E, Wong B, Simon MA: How do US Chinese older adults view elder mistreatment? Findings from a community-based participatory research study. J Aging Health 2011;23:289-312.

34 Pang EC, Jordan-Marsh M, Silverstein M, Cody M: Health-seeking behaviors of elderly Chinese Americans: shifts in expectations. Gerontologist 2003;43:864-874.

35 Cornwell EY, Waite LJ: Measuring social isolation among older adults using multiple indicators from the NSHAP study. J Gerontol B Psychol Sci Soc Sci 2009;64(suppl 1):i38-i46.

36 Schnittker J: Look (closely) at all the lonely people: age and the social psychology of social support. J Aging Health 2007;19:659-682.
37 McPherson M, Smith-Lovin L, Brashears ME Social isolation in America: changes in core discussion networks over two decades. Am Soc Rev 2006;71:353-375.

38 Simon MA, Chen R, Dong X: Gender differences in perceived social support in US Chinese older adults. J Gerontol Geriatr Res 2014;3:163.

39 Okamoto K, Tanaka Y: Gender differences in the relationship between social support and subjective health among elderly persons in Japan. Prev Med 2004;38:318-322.

40 Cornwell B, Schumm LP, Laumann EO, Kim J, Kim YJ: Assessment of social network change in a national longitudinal survey. J Gerontol B Psychol Sci Soc Sci 2014;69(suppl 2):S75-S82. 